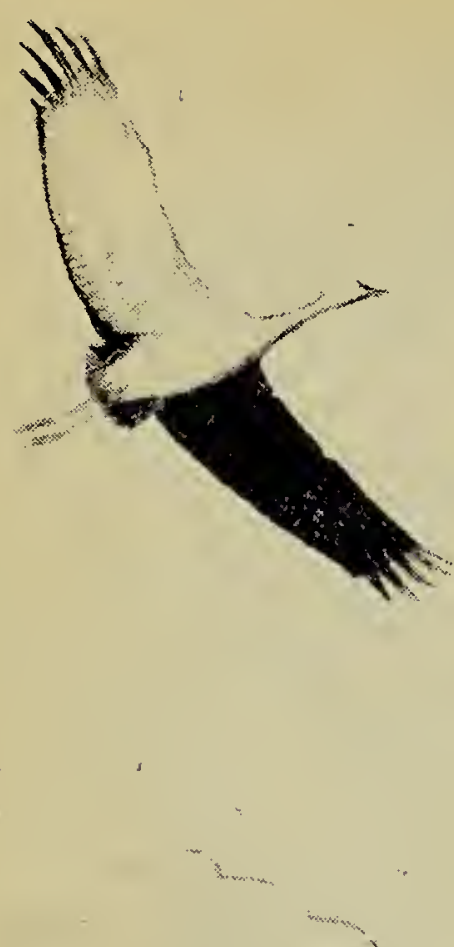

\title{
What about \\ the Sandhill \\ Cranes?
}
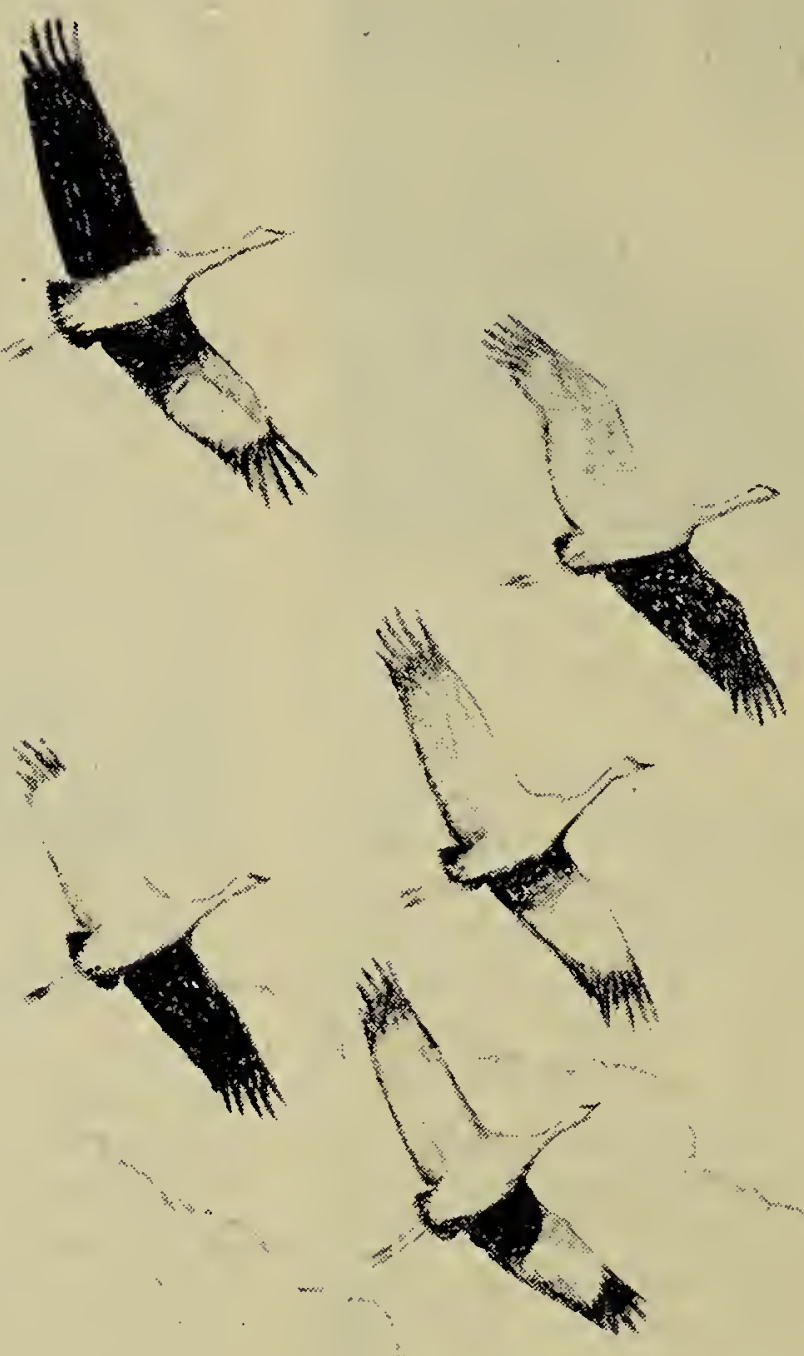

Sketch by F. W. Lahrman

The migrating flocks of Sandhill Cranes which recently wheeled and soared high above us in the spring skies are now nesting in their northern breeding grounds. Before the next issue of the Blue Jay is published in September these great birds will have begun their journey to their wintering grounds in the South. The refuges along the Gulf of Mexico which Fred Bard describes in the previous article provide winter homes for the Sandihll Cranes as well as for the very rare Whooping Cranes. It is not difficult for us to picture these birds resting and feeding in the marshes there, for we in Saskatchewan are among the few people on the continent who have seen thousands of cranes stop to rest and feed as they do in areas like Kindersley or Last Mountain Lake.

Unlike the Whooping Crane, the Sandhill is highly vegetarian and so considerable crop and pasture damage results when these cranes come down to feed for several weeks in agricultural areas. In recognition of this problen, a hunting season for cranes was opened last fall in the Last Mountain Lake area shortly after the memorable trip made by the A.O.U. into the area on August 29 to see the 10,000 Sandhill Cranes that had gathered there. Since then there have been four articles in the Blue Jay on this conservation problem, and the whole matter has received serious discussion at execuitve meetings of the Saskatchewan 


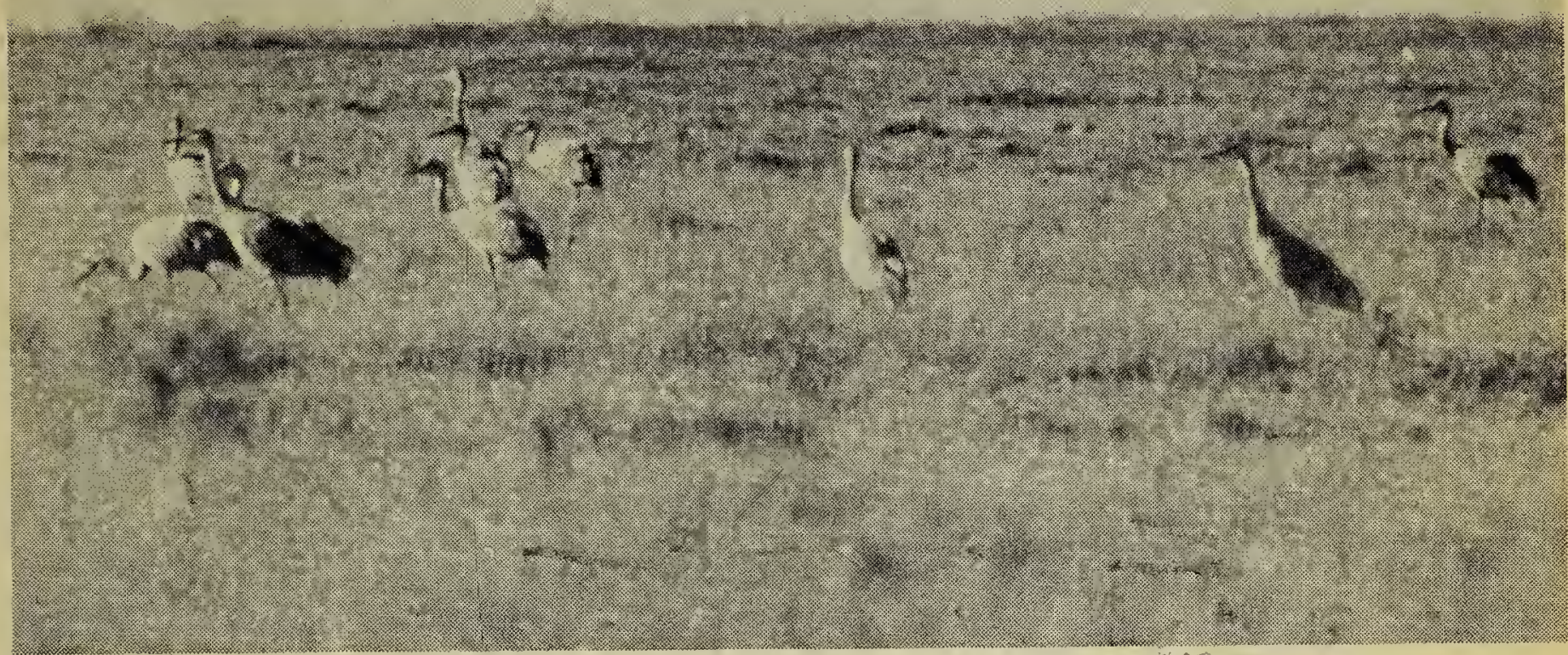

Sandhill Cranes feeding. Last Mountain Lake

Natural History Society. We appreciate the damage caused to grain fields in the area, and are anxious to see that farmers are compensated for this damage in the interim period during which a more final solution to the problem is being sought. On the other hand, we do not want to see the shooting of Sandhill Cranes in this area.

In the first place, the north end of Last Mountain Lake was established long ago as a federal bird sanctuary, the first such sanctuary to be established in the whole of North America, since it dates from 1887. The intention was to provide sanctuary for migrating birds like ducks and cranes, but unfortunately no land was set aside to feed the birds and of course the land right up to the shore of the lake was subsequently taken up for agriculture. Crop damage increased as the birds concentrated more and more in this area. If an adequate area had been set aside for the birds for which the sanctuary was established there would not be the present serious crop damage. We feel that it is important to take this approach even now in solving the crane problem.

One of the main reasons, of course, why naturalists do not wish to see cranes being shot in this area is that the area is very commonly used by the Whooping Crane. Open hunting on cranes seriously threatens the Whooping Crane and may well hasten its extinction, in addition to encouraging an attitude and policy toward the Sandhill Crane that if adopted throughout the continent could reduce that population to the dangerously low level of the now rare Whooping Crane.

Present efforts to solve the crane problem are doomed to failure because two quite contradictory things are being attempted. The present policy endeavours both to protect the farmer and to ask for tolerance of the cranes.

The first method of protection offered the farmer is wildlife cropdamage insurance, but this is not the complete answer to the problem. It is true that the farmer pays only a small premium but at the same time he does not collect full damage, and the hunter who pays most of the cost of insurance is not allowed to hunt cranes. Another method of protection for the farmer is permit shooting. According to the minutes of the Central Flyway Waterfowl Council meeting at Dallas, Texas, March 6, 1960 , an official of the Saskatchewan Wildlife Branch reported approximately 200 cranes killed last fall by special permit. The effectiveness of this method of protection depends 


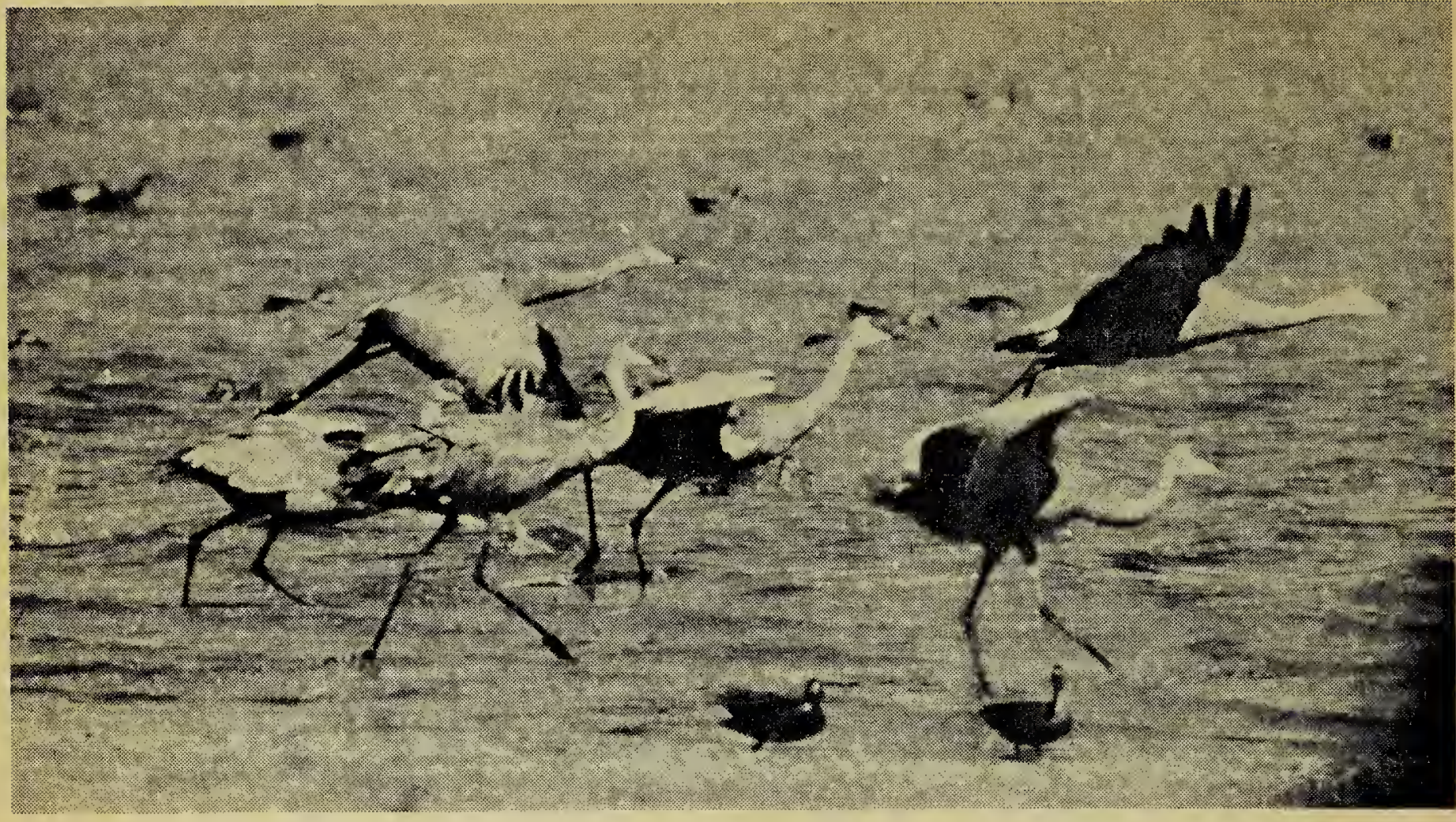

Photo by F. W. Lahrman

Wary Sandhills alerted. Last Mountain Lake

not so much upon the actual reduction in the total crane population as is does in its usefulness in scaring birds away from the field. The farmer will recognize an obvious limitation here-you can scare off birds with a gun only if you are there in person with a gun waiting for the birds, a most impractical arrangement in the busy harvest season! For this reason other scaring devices have been investigated. One of these deterrent devices is advertised on page 73 .

Little work has yet been done to test the effectiveness of these devices in keeping cranes out of crops, although their effectiveness in scaring away ducks is being more fully investigated. The Blue Jay recently reported the use of exploders to keep ducks away from portions of Old Wives' Lake during the outbreak of botulism in 1959 (Vol. XVIII: 24-25). The 1959 cooperative waterfowl depredation investigation of the Canadian Wildlife Service suggests that when acetylene exploders are used for several days in one area to keep ducks away ducks will stay away even for several days after the operation is discontinued. A test made with one exploder in the Last Mountain Lake area last fall suggests that these devices may even be more effective in keeping cranes from crops. One exploder is adequate for a quarter section of crop and will possibly protect as much as 600 to 1200 acres.

The Saskatchewan Natural History Society recommends increased use of crop insurance and scare devices, but it realizes that these are temporary measures. Scare devices simply send the birds on to other fields as they have to feed somewhere. The real answer to the Sandhill Crane problem seems to lie in the expansion of the Department of Natural Resources' policy of planting lure crops. This would make the area a real bird refuge where the cranes could feed without being molested and without damaging privately-owned grain crops. The Society would like to see such an area established and operated for the protection of wildlife and for the recreational opportunities it would provide for the many people who could come to view the spectacular concentration of birds there. We have thought that it would be a particularly happy arrangement if some of the local landowners could be enlisted to manage these lure crops, perhaps leasing or selling their land to the Refuge for such purposes. In any case, the cooperation and constructive suggestions of those who live with the cranes is fundamental in the solution of this conservation problem. 


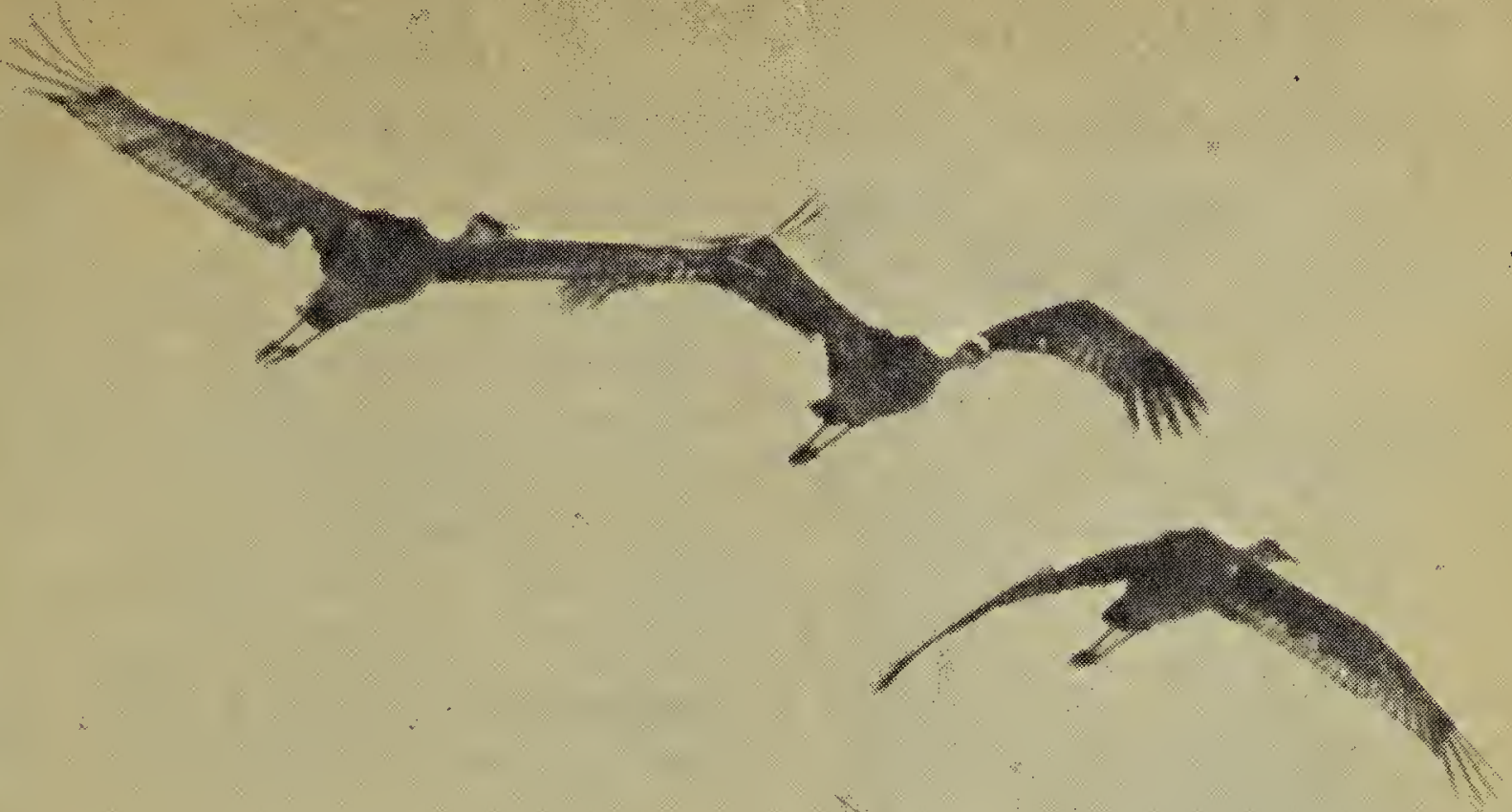

Photo by F. W. Lahrman

Sandhills in flight. Last Mountain Lake

The Saskatchewan Natural History Society recently proposed that the Dept. of Natural Resources establish a wildlife refuge at the end of Last Mountain Lake, especially for the protection of the Whooping Cranes and Sandhill Cranes. This is in line with the resolution re: the protection of Sandhill Cranes passed at the Annual Meeting in October, 1959. If you are interested in the development of such a wildlife refuge, support your Society in its request. Public interest in these projects helps guide governmental policy. It would help if you would write to your IMLA and ask for the establikhment of such a refuge. If you can, send a copy of your letter to the Editor so that the Society knows how much support it has.

\section{Eliminate Sandhill Crane and Duck Damage to Crops}

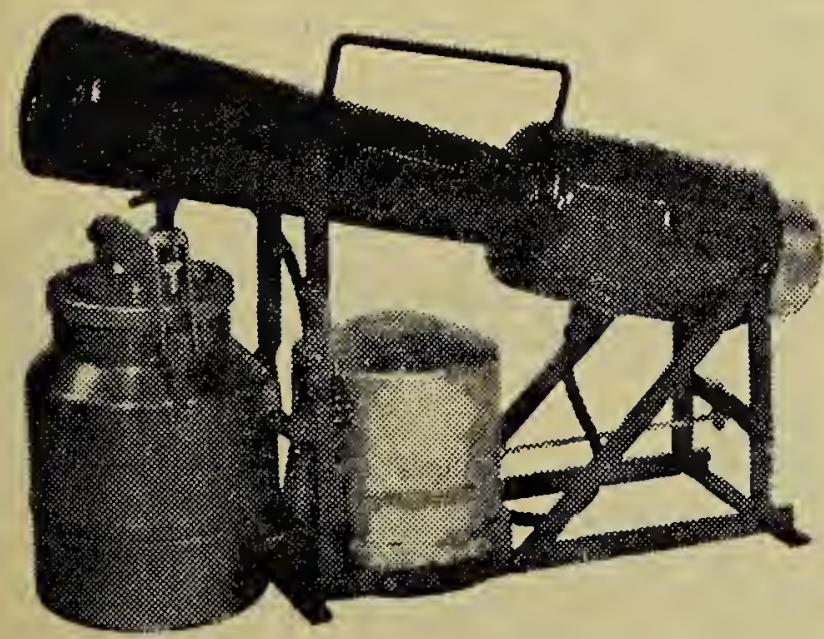

The SCARE-AWAY is a rugged, heavy duty unit operating inexpensively on carbide and water or on acetylene.

The SCARE-AWAY produces fully automatic harmless thunderclap ex- plosions at either regular or irregular intervals which will eliminate forever the loss and nuisance caused by birds in your crops.

The SCARE-AWAY operating on carbide and water costs $\$ 65.00$ in Saskatoon. Since this machine must be serviced once every 24 hours and since it may be difficult to get to the machine during a prolonged spell of wet weather you may want to convert to acetylene. The greater efficiency of the acetylene operation more than pays for the additional $\$ 20$ expense and for the rental charge for the acetylene tank.

The SCARE-AWAY is made in Europe. Investigate now for supplies are limited and time is required for ordering and shipping. Address inquiries to Tom Sterling, 2217 Munroe Ave., Saskatoon.-Advertisement. 